\title{
Modeling the Process of Au Sorption by Natural Sorbents in the Conditions of the Dispersion Train of a Sulfide Tailings
}

\author{
Irina N. Myagkaya*, Bagay-ool Yu. Saryg-ool, \\ Elena V. Lazareva and Sergey M. Zhmodik \\ Sobolev Institute of Geology and Mineralogy SB RAS \\ 3 Koptyug, Novosibirsk, 630090, Russia
}

Received 01.10.2019, received in revised form 30.10.2019, accepted 23.11.2019

The experimental study is aimed at elucidation the laws of Au sorption/deposition by various natural sorbents in an acidic environment $(\mathrm{pH}=2)$. The experiments simulated the conditions of the dispersion train of the Ursk tailings (Kemerovo region, Russia), where active concentration of Au by natural organic matter in an acidic environment is observed. It was found that the degree of extraction of gold from a sulfate solution is generally higher than from chloride solution. This may indicate higher thermodynamic stability of Au chloride complexes in an acidic environment than sulfate ones. Higher deposition rates of gold are observed in solutions with a predominant content of sulfate ions. According to the degree of deposition of $A u$, a series was established (from larger to smaller): a mixture of clay minerals (smectite + palygorskite + muscovite) $>$ humic acids $>$ kaolinite.

Keywords: gold, sorption, tailings, acidic mine drainage.

Citation: Myagkaya I.N., Saryg-ool B.Yu., Lazareva E.V., Zhmodik S.M. Modeling the process of Au sorption by natural sorbents in the conditions of the dispersion train of a sulfide tailings, J. Sib. Fed. Univ. Chem., 2019, 12(4), 580-589. DOI: $10.17516 / 1998-2836-0153$.

(C) Siberian Federal University. All rights reserved

* Corresponding author E-mail address: i_myagkaya@igm.nsc.ru 


\title{
Моделирование процесса сорбции Аu \\ природными сорбентами в условиях \\ потока рассеяния сульфидного хвостохранилища
}

\author{
И.Н. Мягкая, Багай-оол Ю. Сарыг-оол, \\ Е.В. Лазарева, С.М. Жмодик \\ Институт геологии и минералогии им. В.С. Соболева СО РАН \\ Россия, 630090, Новосибирск, пр. Академика Коптюга, 3
}

Выполнено экспериментальное исследование, направленное на выявление закономерностей сорбиии/осаждения Аи различными природными сорбентами в кислой среде (pH=2). Эксперименты моделируют условия потока рассеяния Урского хвостохранилища (Кемеровская область, Россия), где наблюдается активное концентрирование Аи природным органическим веществом в кислой среде. Установлено, что степень извлечения золота из сульфатного раствора виелом выме, чем из хлоридного. Этоможет говорить о большей термодинамической устойчивости хлоридных комплексов Аи в кислой среде, чем сульфатных. В растворах с преобладаюшими содержаниями сульфат-ионов наблюдаются более высокие скорости осаждения золота. Установлен ряд активности природных веществ по степени осаждения Аи (от большего к меньшему): смесь глинистых минералов (смектит + пальгорскит + мусковит) > гуминовые кислоты > каолинит.

Ключевые слова: золото, сорбиия, хвостохранилище, кислый дренажный раствор.

\section{Введение}

В последние годы показана высокая мобильность Аu в некоторых природных и техногенных растворах. Считается, что этому способствуют в том числе анионы-комплексообразователи, наиболее «сильным» из которых является тиосульфат-анион $\mathrm{S}_{2} \mathrm{O}_{3}{ }^{2-}$, прочно связывающий и стабилизирующий $\mathrm{Au}$ в растворе. Анион $\mathrm{S}_{2} \mathrm{O}_{3}{ }^{2-}$ в природе преимущественно образуется при окислительном выщелачивании сульфидсодержащего вещества, примерами которого могут служить отходы обогащения сульфидных руд [1]. Тиосульфатное выщелачивание золота из руд рассматривается как альтернатива цианированию [2]. Кроме того, экспериментально установлено существование и высокая мобильность в растворах кластеров и наночастиц золота, стабилизированных крупными органическими лигандами $[3,4]$.

Многие природные материалы способны сорбировать золото из раствора: сульфиды [5], соединения Fe, Mn (оксиды и гидроксиды) [6], органическое вещество (в частности, гуминовые кислоты) [7], силикаты (глины) [8, 9]. Сорбционные свойства по отношению к золоту проявляют также различные микроорганизмы [10].

В ореоле рассеяния Урского хвостохранилища, которое было сформировано более 80 лет назад и сложено сульфидсодержащими отходами обогащения Аu-содержащих руд (Россия, Кемеровская область, координаты 54²7’11.03”C, 85²4’09.76”В), авторами установлено кон- 
центрирование Au природным органическим веществом до содержаний 155-342 г/т из кислого дренажного раствора $[1,11-15]$. Отходы складированы в естественном логу в виде двух куч, не закреплены и на протяжении истории хранения размывались сезонными осадками и сносились в заболоченный лог, где до настоящего времени располагаются остатки болотных кочек. Природный ручей, дренируя отвалы, превращался в сильнокислый (pH 1.9, Eh 655 мВ) дренажный ручей (КДР) Al-Fe-SO $\mathrm{SO}_{4}$ состава с минерализацией 4.8 г/л. Он содержит значительные концентрации токсичных элементов, а также Аu (1.2 мкг/л) [11]. Золото концентрируется органическим веществом как в ассоциации с гидроксидами железа, так и при их отсутствии $[12,13$, 15]. Одними из основных минералов системы являются гидрослюды и глинистые минералы (иллит, каолинит, минералы группы смектита). Цель настоящего исследования - оценить возможность осаждения золота глинистыми веществами и гуминовыми кислотами из растворов различного состава. Состав растворов выбирали таким образом, чтобы смоделировать процесс осаждения металла в потоке рассеяния Урского хвостохранилища.

\section{Методы исследования}

\section{Экспериментальная часть}

Выбраны три типа природных сорбентов: 1) глина I (с преобладанием мусковита, смектита и палыгорскита); 2) глина II (в которой преобладает каолинит), 3) гуминовые кислоты.

Из глин методом отмучивания была выделена фракция <1 мкм [16]. Для экспериментов использовали гуминовый препарат, который был получен из гуминовых веществ бурых углей выделением раствором $\mathrm{NaOH}$. Препарат растворяли и подкисляли раствором $\mathrm{HCl}$ до $\mathrm{pH}=1$ (по индикаторной бумаге), осаждали гуминовые кислоты, центрифугировали и декантировали для отделения от фульвовых кислот, затем промывали несколько раз дистиллированной водой до нейтральной реакции (по индикаторной бумаге).

Эксперименты проводили в двух средах: хлоридной и сульфатной. Хлоридная среда представляет собой хлоридный буфер (12 мл 1 M раствора $\mathrm{HCl}($ осч) и 5.14 г $\mathrm{NaCl}($ хч) до 1 л) с $\mathrm{pH}=2$ и концентрацией хлорид-ионов $0.1 \mathrm{M}$. Часть раствора $\mathrm{HCl}$ заменяли солянокислым раствором Аu с концентрацией 1 ppm.

Сульфатная среда также представляет собой буфер (14.2 г безводного $\mathrm{Na}_{2} \mathrm{SO}_{4}$ (хч) и 35 мл $1 \mathrm{M}$ раствора $\mathrm{HCl}($ осч) до 1 л) с $\mathrm{pH}=2$ и концентрацией сульфат-ионов $0.1 \mathrm{M}$. Часть раствора $\mathrm{HCl}$ также заменяли солянокислым раствором Аu с концентрацией 1 ppm. Исходная концентрация $\mathrm{Au}$ в обеих средах до начала экспериментов составляет $10 \mathrm{ppb}\left(5.1 \cdot 10^{-8} \mathrm{M}\right)$.

В приготовленные Аu-содержащие среды вносят навеску сорбента в 1 г. Аликвоты объемом 5 мл отбирали по следующей схеме: сразу после внесения сорбента, далее через 15, 30 мин, $1,3,6,12,24,48,72$ ч. До отбора аликвоты измеряли рН и Еһ растворов, после отбора растворы тщательно перемешивали. Отобранные аликвоты без дополнительной обработки подкисляли до $2 \mathrm{M}$ раствора $\mathrm{HCl}$, затем экстрагировали $0.1 \mathrm{M}$ раствором сульфидов нефти в толуоле для количественного определения золота.

\section{Инструментально-аналитические методы}

$\mathrm{pH}$ и Еh в растворах измеряли потенциометрическим методом, используя анализатор «Анион 7051» («Инфраспак-Аналит», Россия). 
Определение содержания Аu в аликвотах и в сорбентах (до и после экспериментов) проводили методом атомно-абсорбционной спектрометрии (AАC) с пламенной и электротермической атомизацией проб (спектрометр Solar M6, Thermo Electron, США) согласно методике НСАМ №237-С [17], модифицированной по рекомендациям В.Г. Цимбалист [18].

Определение минерального состава веществ, используемых для экспериментов (глина I и II), осуществляли методом порошковой рентгеновской дифрактометрии. Образец для съемки истирали в спирте, чтобы не нарушить структурное состояние слагающих его минералов, наносили на стеклянную подложку и высушивали при комнатной температуре. Плотность образца 20 мг/см². Рентгеновскую съемку проводили на порошковом автоматическом дифрактометре ДРОН-4 (излучение $\mathrm{Cu} K_{\alpha}$, графитовый монохроматор), напряжение 40 кв, ток 25 ма. Съемка проведена в области углов $2 \theta$ от 2 до $65^{\circ}$. Дифракционные картины были отсканированы в интервале $2 \theta$ от 2 до $65^{\circ}$ с шагом $0.05^{\circ}$, время сканирования в точке $-4 \mathrm{c}$.

\section{Результаты и обсуждение}

Эксперимент проводили до достижения равновесия Аu с используемым сорбентом. В обеих средах значение $\mathrm{pH}$ поддерживалось в заданном диапазоне (1.97-2.00) на протяжении всего времени проведения эксперимента. В модельных средах золото достаточно устойчиво и удерживается в растворе в течение всего времени эксперимента (согласно результатам холостого эксперимента).

По результатам эксперимента по разности между исходной концентрацией и концентрацией металла в растворе после сорбции рассчитывали величину адсорбиии (A, мح/2), а также степень извлечения золота из раствора (рис. 1).

В хлоридной среде (рис. 1а-б) в первый час эксперимента глина I, а также гуминовый препарат показали схожие закономерности - первые 30 мин количество сорбированного элемента увеличивается и затем немного снижается. При добавлении гуминового препарата сорбция более интенсивная, чем при добавлении глины I (табл. 1). За первые 4 ч происходит сорбция на 2030 \% в случае добавления в раствор глины I и гуминового препарата, а за 12 ч - 55-60 \%, далее наблюдается снижение скорости сорбции, причем для гуминового препарата идет тенденция к установлению равновесия, а в растворе со смесью глинистых минералов I сорбция продолжается. Через 48 ч для гуминового препарата достигается равновесие, тогда как в растворе с глиной I сорбция продолжается. В ходе эксперимента степень извлечения (рис. 1б) золота из раствора гуминовым препаратом составила $85 \%$, глиной I - $95 \%$.

При добавлении в хлоридный раствор глины II (каолинитовой) золото сорбируется по сравнению с первыми двумя сорбентами менее интенсивно (рис. 1a); в первый час количество сорбированного элемента медленно и постоянно увеличивается, достигая величины сорбции, близкой той, что установлена для гуминового препарата за это же время. За 12 ч сорбируется $30 \%$ элемента и 65 \% - за 24 ч. К 48 ч, как и для гуминового препарата, устанавливается равновесие. Значения величин адсорбции представлены в табл. 1. Величина извлечения золота сорбентом данного типа самая низкая (рис. 16) - $82 \%$.

Из сульфатного раствора (рис. 16-г) золото сорбируется более интенсивно, чем из хлоридного. В первые 15 мин, как и в хлоридном растворе, для всех сорбентов наблюдается рост величины адсорбции (табл. 1) и содержание золота резко снижается в первые минуты проведе-

$$
-583-
$$


Irina N. Myagkaya, Bagay-ool Yu. Saryg-ool... Modeling the Process of Au Sorption by Natural Sorbents...
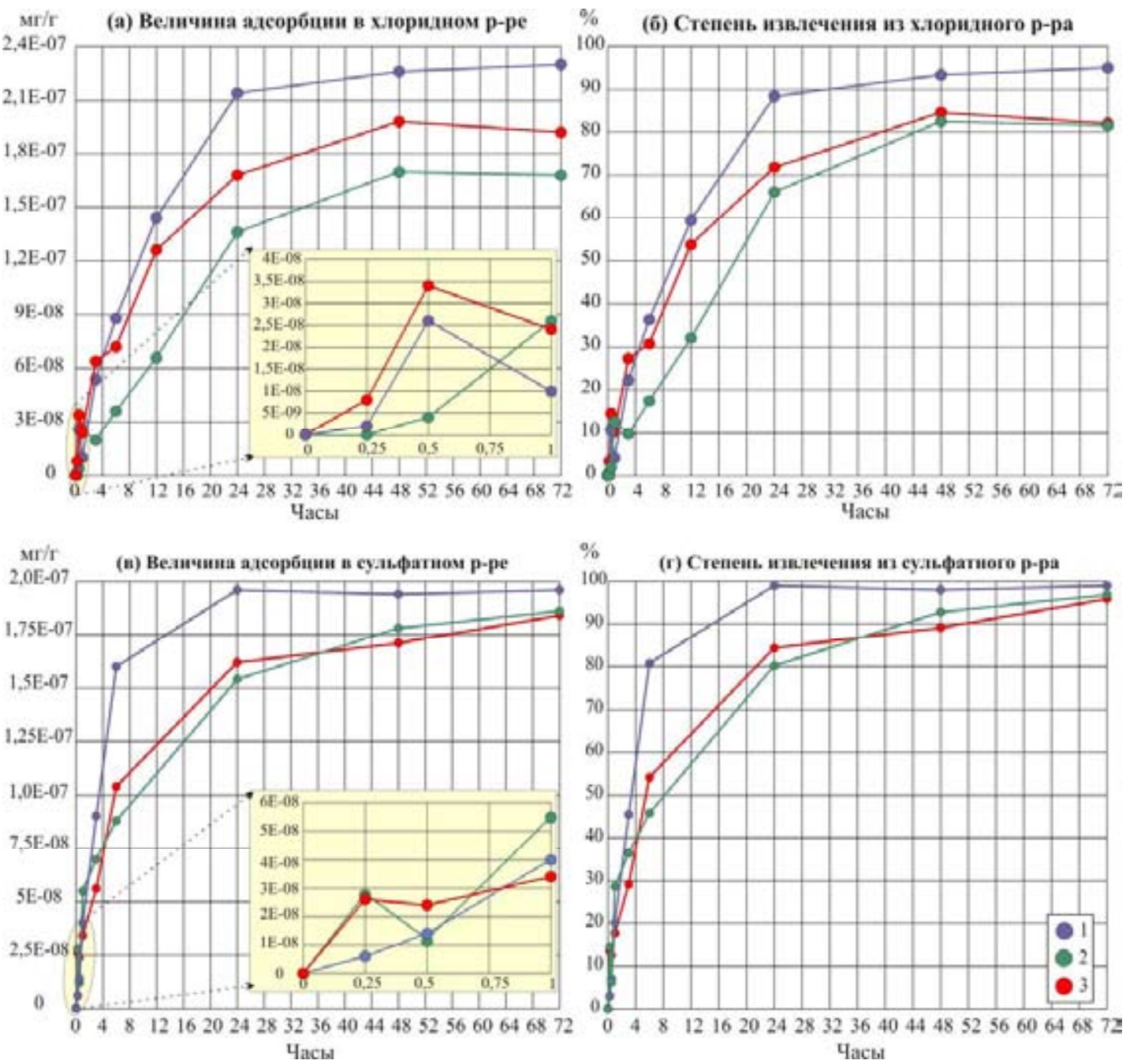

Рис. 1. Кинетические кривые сорбции (а, в) и степень извлечения $(б$, г) золота в/из хлоридном/ого (а, б) и сульфатном/ого (в, г) растворах/ов: 1 - глина I; 2 - глина II; 3 - гуминовые кислоты; желтым выделена область, отвечающая первому часу эксперимента

Fig. 1. Kinetic curves sorption (a, c) and degree of extraction (b, d) of gold in/from chloride and sulphate solutions: 1 - clay I; 2 - clay II; 3 - humic acids; the area corresponding to the first hour of the experiment is highlighted in yellow

ния эксперимента. Наименьшая скорость снижения концентрации золота, как и в хлоридном растворе, установлена в эксперименте с добавлением глины II (с преобладанием каолинита); у глины I и гуминового препарата - близкие показатели. Интенсивность сорбции в сульфатном растворе падает (рис. 18) через 30 мин взаимодействия с гуминовым препаратом и глиной I, тогда как в хлоридном растворе те же показатели достигаются только через 1 ч. Значения величин адсорбции представлены в табл. 1. У глины II в сульфатном растворе постоянно нарастающая сорбция с 30 мин после начала эксперимента и равновесие под конец эксперимента (72 ч) не достигается. При этом максимальная степень извлечения составила 96.9 \%. Для двух других сорбентов спустя час после начала наблюдается постоянный рост величины адсорбции 
Таблица 1. Изменение величины адсорбции (мг/г) от времени

Table 1 . The change of the adsorption value $(\mathrm{mg} / \mathrm{g})$ over the time

\begin{tabular}{|c|c|c|c|c|c|c|}
\hline \multirow{2}{*}{ Часы } & \multicolumn{2}{|c|}{ Гуминовые кислоты } & \multicolumn{2}{|c|}{ Глина II } & \multicolumn{2}{c|}{ Глина I } \\
\cline { 2 - 7 } & $\mathrm{Cl}$-p & $\mathrm{SO}_{4} \mathrm{p}-\mathrm{p}$ & $\mathrm{Cl} \mathrm{p}-\mathrm{p}$ & $\mathrm{SO}_{4} \mathrm{p}-\mathrm{p}$ & $\mathrm{Cl} \mathrm{p}-\mathrm{p}$ & $\mathrm{SO}_{4} \mathrm{p}-\mathrm{p}$ \\
\hline 0 & 0 & 0 & 0 & 0 & 0 & 0 \\
\hline 0,25 & $8,00 \mathrm{E}-09$ & $2,60 \mathrm{E}-08$ & 0 & $2,80 \mathrm{E}-08$ & $2,00 \mathrm{E}-09$ & $6,00 \mathrm{E}-09$ \\
\hline 0,5 & $3,40 \mathrm{E}-08$ & $2,40 \mathrm{E}-08$ & $4,00 \mathrm{E}-09$ & $1,20 \mathrm{E}-08$ & $2,60 \mathrm{E}-08$ & $1,40 \mathrm{E}-08$ \\
\hline 1 & $2,40 \mathrm{E}-08$ & $3,40 \mathrm{E}-08$ & $2,60 \mathrm{E}-08$ & $5,50 \mathrm{E}-08$ & $1,00 \mathrm{E}-08$ & $4,00 \mathrm{E}-08$ \\
\hline 3 & $6,40 \mathrm{E}-08$ & $5,60 \mathrm{E}-08$ & $2,00 \mathrm{E}-08$ & $7,00 \mathrm{E}-08$ & $5,40 \mathrm{E}-08$ & $9,00 \mathrm{E}-08$ \\
\hline 6 & $7,20 \mathrm{E}-08$ & $1,04 \mathrm{E}-07$ & $3,60 \mathrm{E}-08$ & $8,80 \mathrm{E}-08$ & $8,80 \mathrm{E}-08$ & $1,60 \mathrm{E}-07$ \\
\hline 12 & $1,26 \mathrm{E}-07$ & н.д. & $6,60 \mathrm{E}-08$ & н.д. & $1,44 \mathrm{E}-07$ & н.д. \\
\hline 24 & $1,68 \mathrm{E}-07$ & $1,62 \mathrm{E}-07$ & $1,36 \mathrm{E}-07$ & $1,54 \mathrm{E}-07$ & $2,14 \mathrm{E}-07$ & $1,96 \mathrm{E}-07$ \\
\hline 48 & $1,98 \mathrm{E}-07$ & $1,71 \mathrm{E}-07$ & $1,70 \mathrm{E}-07$ & $1,78 \mathrm{E}-07$ & $2,26 \mathrm{E}-07$ & $1,94 \mathrm{E}-07$ \\
\hline 72 & $1,92 \mathrm{E}-07$ & $1,84 \mathrm{E}-07$ & $1,68 \mathrm{E}-07$ & $1,86 \mathrm{E}-07$ & $2,30 \mathrm{E}-07$ & $1,96 \mathrm{E}-07$ \\
\hline
\end{tabular}

Примечание: н.д. - нет данных.

(рис. 18). За первые три часа происходит сорбция 20-30 \% золота, за 6 ч - 45 \% для глины II, 55 \% для гуминового препарата и 80 \% для глины І. Для всех случаев наблюдается практически полная сорбция золота (>95 \%), причем для глины I она достигается за 24 ч, а для глины II и гуминового препарата - за 72 ч.

Концентрации золота в сорбентах до эксперимента составили: глина I - 2 г/т, глина II 0.004 г/т, гуминовые кислоты - 0.004 г/т. Концентрации после эксперимента были равны: глина I - 11.5, глина II - 9.5 г/т, гуминовый препарат - 6.4 г/т.

Результаты экспериментов показывают, что физико-химические свойства растворов, содержащих золото (в данном случае $\mathrm{pH}$ и основной анионный состав), существенно влияют на характер и величину сорбции $\mathrm{Au}$ различными природными материалами. Для растворов c $\mathrm{pH}=2$ и различным анионным составом в рамках проведенных экспериментов наблюдалась существенная подвижность элемента (то есть существование в растворе значительный промежуток времени без изменения его концентрации).

Анионный состав раствора и, следовательно, формы существования золота в нем являются главными факторами, влияющими на сорбцию элемента различными материалами. Так, в хлоридной среде, для которой характерен устойчивый комплекс золота $\left[\mathrm{AuCl}_{4}\right]^{-}[3] \mathrm{c}$ константой устойчивости $\log \left(\beta_{4}\right)=21.30$, наблюдается длительная и в ряде случаев неполная сорбция золота изучаемыми сорбентами (в рамках проведенных экспериментов). В сульфатной среде происходит быстрая и практически полная сорбция золота. При избытке сульфатионов предполагается образование менее устойчивых, смешанных хлоридно-сульфатных комплексов золота $\mathrm{Au}\left[\mathrm{Cl}_{3}\left(\mathrm{SO}_{4}\right)\right]^{2-}$ (аналогично образованию аквагидроксосульфатных комплексов типа $\left.\mathrm{Au}\left[(\mathrm{OH})\left(\mathrm{H}_{2} \mathrm{O}\right)\left(\mathrm{SO}_{4}\right)_{2}\right]^{-}[19]\right)$, однако подобные комплексы остаются практически не изученными.

Вторым существенным фактором, оказывающим влияние на сорбцию золота, является состав сорбента. Сорбционная активность глин (а также других силикатов) в кислых условиях 
(до $\mathrm{pH}=3$ ) зависит в первую очередь от удельной поверхности вещества [20]. Описываемый в литературе механизм сорбции золота глинами (на примере каолинита и пирофиллита) в кислых условиях предполагает несколько ступеней: (1) электростатическое взаимодействие анионных водных комплексов золота (электроотрицательных) с положительно заряженной поверхностью глин и протонированными силанольными группами на поверхности каркасных силикатов; (2) хемосорбция золота на дефектных участках силикатов с заменой лиганда на гидроксильную группу на поверхности силиката; (3) восстановление Au (III) до металлического, где в качестве восстановителя служат ионы и радикалы, образуемые в результате взаимодействия глин с водой и при механической активации (разрыв связей Si-O) [21]. Кроме того, возможно внедрение наночастиц золота в межслоевое (или пластинчатое) пространство глин [22]. Активированный кислотой монтмориллонит частично расслаивается, имеет более высокую удельную поверхность и содержит микро- и мезопоры диаметром 0-10 нм [23]. Активированный азотной кислотой монтмориллонит имеет площадь удельной поверхности 327-579 $\mathrm{M}^{2} / \Gamma$, большой удельный объем пор $\sim 0.7 \mathrm{~cm}^{3} / \Gamma$ и диаметр пор 0-10 нм, что приводит к формированию наночастиц золота размером 0-10 нм, которые распределяются равномерно по подложке в ходе сорбции, трансформируясь из $\left[\mathrm{AuCl}_{4}\right]^{-}$комплекса [24]. Механизм взаимодействия золота с природным органическим веществом до конца не установлен, но известны следующие процессы, влияющие на его концентрирование: восстановление ионного золота растворенными органическими соединениями и дальнейшая его стабилизация слоем органических молекул [25]; сорбция, вызванная комплексообразованием ионного золота с функциональными группами органических веществ, а также глинистыми частицами и гидроксидами железа (благодаря химической и физической сорбции) [26]; биосорбция [27]; сорбция на аутигенных сульфидах, образующихся на органическом веществе в результате восстановления сульфат-ионов [28]. Известно, что при взаимодействии растворенного золота с природным органическим веществом происходит восстановление первого с последующим образованием наночастиц золота [29]. В данном механизме органическое вещество выступает восстановителем и в дальнейшем стабилизатором наночастиц золота [30]. Следует отметить, что данный механизм изучен при взаимодействии высоких концентраций золота с органическим веществом (от 0.005 до 10 масс. \% Au на органическое вещество). Образование промежуточных комплексов золота (III) с органическими лигандами, которые и обеспечивают высокую мобильность золота в органосодержащих средах [31], в природных условиях с помощью инструментальных методов достоверно не установлено. Не исключено, что механизм взаимодействия/сорбции сопровождается первоначальным образованием комплексов золота с органическими лигандами (преимущественно S-содержащими), при превышении некоторой пороговой концентрации золота он запускает дальнейший механизм образования наночастиц.

\section{Заключение}

Влияние разных типов сорбентов с разными структурами на сорбцию золота в кислых условиях отражается в наших экспериментах. Смесь глинистых минералов и гидрослюд (глина I) показала наибольшую сорбционную активность (как по величине, так и по скорости) по отношению к золоту. По данным кривых сорбции, смесь глинистых минералов и гидрослюд полностью сорбирует золото как из хлоридных, так и из сульфатных растворов. Каолинитовая 
глина (глина II) и гуминовые кислоты также сорбируют золото из сульфатных растворов полностью, но в хлоридных растворах устанавливается равновесие «Аи в растворе - сорбированное $\mathrm{Au».} \mathrm{Наблюдаемые} \mathrm{различия} \mathrm{объясняются} \mathrm{меньшей} \mathrm{устойчивостью} \mathrm{сульфатных} \mathrm{комплек-}$ сов золота. Однако для подтверждения этих выводов необходимо проведение более детального исследования.

Эксперименты по моделированию условий потока рассеяния Урского хвостохранилища показали, что степень извлечения золота из сульфатного раствора в целом выше, чем из хлоридного. Это может свидетельствовать о большей термодинамической устойчивости хлоридных комплексов в кислой среде, чем сульфатных. Исследованные сорбенты осаждают Аи в ряду (от большего к меньшему): смесь глинистых минералов (смектит+палыгорскит+мусковит) > гуминовый препарат > каолинит.

Работа выполнена по государственному заданию ИГМ СО РАН в ЦКП «Многоэлементных и изотопных исследований СО РАН» (Новосибирск, Россия). Также исследование поддержано грантами РФФИ 16-35-60108 и 19-05-00464.

\section{Список литературы}

1. Myagkaya I.N., Lazareva E.V., Gustaytis M.A., Zhmodik S.M. Gold and silver in a system of sulfide tailings. Part 1: Migration in water flow. Journal of Geochemical Exploration 2016. Vol. 160, P. $16-30$.

2. Xu B., Kong W., Li Q., Yang Y., Jiang T., \& Liu X. A review of thiosulfate leaching of gold: Focus on thiosulfate consumption and gold recovery from pregnant solution. Metals 2017. Vol. 7(6), P. 222.

3. Гринвуд Н., Эрншо А. Химия элементов. В 2 т. (Пер. с англ. В.А. Михайлова и др.) М.: Бином. Лаб. знаний, 2008. Т. 2. 670 c. [Greenwood N., Earnshaw A. Chemistry of the Elements. In two volumes (Translation from English of Mikhailov V.A. et al.). Moscow: Binom. Lab. Znanii, 2008. Vol. 2. 670 p. (In Russ.)]

4. Giljohann D.A., Seferos D.S., Daniel W.L., Massich M.D., Patel P.C., Mirkin C.A. Gold nanoparticles for biology and medicine. Angewandte Chemie International Edition 2010. Vol. 49(19), P. 3280-3294.

5. Mycroft J.R., Bancroft G.M., McIntyre N.S., Lorimer J.W. Spontaneous deposition of gold on pyrite from solutions containing $\mathrm{Au}$ (III) and $\mathrm{Au}$ (I) chlorides. Part I: A surface study. Geochimica et Cosmochimica Acta 1995. Vol. 59(16), P. 3351-3365.

6. Roslyakov N.A., Belevantsev V.I., Kalinin Y.A. Supergene gold in manganese-bearing weathered rocks. Geochemistry International 2005. Vol. 43(9), P. 928-931.

7. Ran Y., Fu J., Rate A.W., Gilkes R.J. Adsorption of Au (I, III) complexes on Fe, Mn oxides and humic acid. Chemical Geology 2002. Vol. 185(1-2), P. 33-49.

8. Жмодик С.М., Миронов А.Г., Кренделев Ф.П. Экспериментальное исследование распределения золота на природных сорбентах с использованием радиоизотопа ${ }^{195} \mathrm{Au}$. Литология и полезные ископаемые 1980. №3, C. 153-158. [Zhmodik S.M., Mironov A.G., Krendelev F.P. Experimental study of gold distribution on natural sorbents using radioisotope ${ }^{195} \mathrm{Au}$. Lithology and mineral resources 1980. Vol. 3, P. 153-158. (In Russ.)]

$$
-587-
$$


9. Hong H., Sun Z., Fu Z., Min X. Adsorption of $\mathrm{AuCl}_{4}^{-}$by Kaolinites: Effect of pH, Temperature and Kaolinite Crystallinity. Clays and clay minerals 2003. Vol. 51(5), P. 493-501.

10. Etschmann B., Brugger J., Fairbrother L., Grosse C., Nies D.H., Martinez-Criado G., Reith F. Applying the Midas touch: Differing toxicity of mobile gold and platinum complexes drives biomineralization in the bacterium Cupriavidus metallidurans. Chemical Geology 2016. Vol. 438, P. 103-111.

11. Myagkaya I.N., Lazareva E.V., Gustaitis M.A., Zayakina S.B., Polyakova E.V., Zhmodik S.M. Gold in the sulfide waste-peat bog system as a behavior model in geological processes. Doklady Earth Sciences 2013. Vol. 453(2), P. 201-206.

12. Myagkaya I.N., Lazareva E.V., Gustaytis M.A., Zhmodik, S.M. Gold and silver in a system of sulfide tailings. Part 2: reprecipitation on natural peat. Journal of Geochemical Exploration 2016. Vol. 165, P. 8-22.

13. Saryg-ool B.Y., Myagkaya I.N., Kirichenko I.S., Gustaytis M.A., Shuvaeva O.V., Zhmodik S.M., Lazareva E.V. Redistribution of elements between wastes and organic-bearing material in the dispersion train of gold-bearing sulfide tailings: Part I. Geochemistry and mineralogy. Science of the Total Environment 2017. Vol. 581, P. 460-471.

14. Saryg-ool B.Y., Myagkaya I.N., Kirichenko I.S., Gustaytis M.A., Shuvaeva O.V., Zhmodik S.M., Lazareva E.V. Redistribution and Speciation of Elements in Gold-bearing Sulfide Mine Tailings Interbedded with Natural Organic Matter: Case Study of Novo-Ursk Deposit, Kemerovo Region, Siberia. Geochemistry: Exploration, Environment, Analysis 2019. In press.

15. Lazareva E.V., Myagkaya I.N., Kirichenko I.S., Gustaytis M.A., Zhmodik S.M. Interaction of natural organic matter with acid mine drainage: In-situ accumulation of elements. Science of the Total Environment 2019. Vol. 660, P. 468-483.

16. Lazareva E.V., Zhmodik S.M., Dobretsov N.L., Tolstov A.V., Shcherbov B.L., Karmanov N.S., Gerasimov E.Yu., Bryanskaya A.V. Main minerals of abnormally high-grade ores of the Tomtor deposit (Arctic Siberia). Russian Geology and Geophysics 2015. Vol. 56(6), P. 844-873.

17. Методика МВИ НСАМ № 237-С. Определение золота экстракционно-атомноабсорбционным методом с органическими сульфидами в минеральном сырье разнообразного состава. Отраслевая методика III категории точности. Москва, 2006. [Methods of Measurements MVI NSAM № 237-S. Extraction AAS determination with organic sulfides of Au in mineral materials of different compositions. Moscow, 2006. (In Russ.)]

18. Цимбалист В.Г. Методы определения золота и серебра при геохимических исследованиях. Метод. разработки. Новосибирск: Изд-во Института геологии АН СССР, 1980. 46 с. [Tsimbalist V.G. Methods of $\mathrm{Au}$ and Ag determination in Geochemical Research: Methodological Guidelines. Novosibirsk: Publishing IgG SB AS USSR, 1980. 46 p. (In Russ.)]

19. Mironov I. V., Makotchenko E. V. On the existence of gold (III) complex species in acid sulfate solutions. Russian journal of inorganic chemistry 2005. Vol. 50(5), P. 799-804.

20. Mohammadnejad S., Provis J.L., van Deventer J.S. Gold sorption by silicates in acidic and alkaline chloride media. International Journal of Mineral Processing 2011. Vol. 100(3-4), P. 149-156.

21. Mohammadnejad S., Provis J.L., van Deventer J.S. Reduction of gold (III) chloride to gold (0) on silicate surfaces. Journal of colloid and interface science 2013. Vol. 389(1), P. 252-259. 
22. Belova V., Möhwald H., Shchukin D.G. Sonochemical intercalation of preformed gold nanoparticles into multilayered clays. Langmuir 2008. Vol. 24(17), P. 9747-9753.

23. Komadel P., Madejová J. Chapter 7.1 Acid activation of clay minerals. Developments in Clay Science 2006. Vol. 1, P. 263-287.

24. Borah B.J., Dutta D., Dutta D.K. Controlled nanopore formation and stabilization of gold nanocrystals in acid-activated montmorillonite. Applied Clay Science 2010. Vol. 49(3), P. 317-323.

25. Avramenko V.A., Bratskaya S.Y., Yakushevich A.S., Voit A.V., Ivanov V.V., Ivannikov S.I. Humic acids in brown coals from the southern Russian Far East: general characteristics and interactions with precious metals. Geochemistry International 2012. Vol. 50(5), P. 437-446.

26. Varshal G.M., Velyukhanova T.K., Chkhetiya D.N., Kholin Y.V., Shumskaya T.V., Tyutyunnik O.A., Koshcheeva I.Ya., Korochantsev A.V. Sorption on humic acids as a basis for the mechanism of primary accumulation of gold and platinum group elements in black shales. Lithology and Mineral Resources 2000. Vol. 35(6), P. 538-545.

27. Kuimova N.G., Pavlova L.M., Sorokin A.P. Biogenic gold accumulation in brown coals at the peat stage. Doklady Earth Sciences 2012. Vol. 443(1), P. 347-352.

28. Юдович Я.Э., Кетрис М.П. Золото в углях. Тр. Ин-та геологии Коми НЦ УрО РАН 2004, T. (116), C. 80-109. [Yudovich Ya.E., Ketris M.P. Gold in coals. Proceedings of Institute of geology Komi SC UrB RAS 2004, Vol. (116), P. 80-109. (In Russ.)]

29. Yin Y., Yu S., Liu J., Jiang G. Thermal and photoinduced reduction of ionic Au (III) to elemental $\mathrm{Au}$ nanoparticles by dissolved organic matter in water: possible source of naturally occurring $\mathrm{Au}$ nanoparticles. Environmental science \& technology 2014. Vol. 48(5), P. 2671-2679.

30. Machesky M.L., Andrade W. O., Rose A.W. Interactions of gold (III) chloride and elemental gold with peat-derived humic substances. Chemical Geology 1992. Vol. 102(1-4), P. 53-71.

31. Wood S. A. The role of humic substances in the transport and fixation of metals of economicinterest (Au, Pt, Pd, U, V). Ore Geology Reviews 1996. Vol. 11(1-3), P. 1-31. 